\title{
Short communication: Effect of feeding pooled and nonpooled high-quality colostrum on passive transfer of immunity, morbidity, and mortality in dairy calves
}

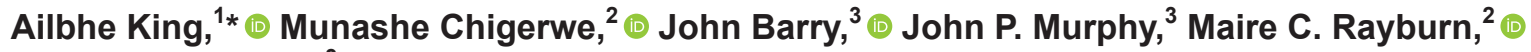 \\ and Emer Kennedy ${ }^{3}$ (i) \\ ${ }^{1}$ William Pritchard Veterinary Medical Teaching Hospital, 1 Garrod Drive, Davis, CA 95616 \\ ${ }^{2}$ Department of Medicine and Epidemiology. University of California-Davis, 1275 Health Sciences Drive, Davis 95616 \\ ${ }^{3}$ Teagasc, Animal \& Grassland Research and Innovation Centre, Moorepark, Fermoy, Co. Cork P61 C996, Ireland
}

\begin{abstract}
Pooling colostrum is commonly practiced on Irish dairy farms. Pooling can result in dilution when colostrums with high and low IgG concentrations are mixed, thereby predisposing calves to failure of passive immunity. The objectives of this study were to compare IgG concentrations in colostrum from individual cows with colostrum pooled from several cows, and assess serum IgG concentrations, morbidity, and mortality among calves fed colostrum from their own dam, from a different cow, or pooled from several cows. We hypothesized that pooling colostrum reduces IgG concentration due to dilution compared with colostrum from individual cows, and that calves fed pooled colostrum achieve lower serum IgG concentrations than calves fed colostrum from individual cows. Calves were randomly assigned to 1 of 3 groups: (1) fed colostrum from their own dam $(\mathrm{n}=20)$; (2) fed colostrum from a different dam $(\mathrm{n}=20)$; or $(3)$ fed pooled colostrum $(\mathrm{n}=18)$. A sample of colostrum fed to each calf was collected. Serum samples were collected from calves at birth (0 h) and at $24 \mathrm{~h}$ after colostrum feeding. Colostrum and serum IgG concentrations were measured by radial immunodiffusion. Calves were weighed at birth and at weaning, and the health status of each calf was assessed twice daily. Health assessment was based on general demeanor, rectal temperature, fecal consistency, respiratory rate, and the presence of cough, nasal, or ocular discharge. Colostrum and serum IgG concentrations, and weaning weights were compared using ANOVA. Associations between group and morbidity or mortality rates were compared using $\chi^{2}$ or Fisher's exact tests. Median and $95 \%$ confidence intervals (95\% CI) of IgG concentrations of colostrum were 99.4 (81.8-111.5),
\end{abstract}

Received May 25, 2019.

Accepted October 7, 2019.

*Corresponding author: aeeking@ucdavis.edu
95.2 (84.1-107.2), and 100.7 (90.5-104.4) g/L for own dam, different dam, and pooled groups, respectively. We did not find any differences in colostrum IgG concentrations among the colostrum sources. Median (95\% CI) serum IgG concentrations at $24 \mathrm{~h}$ were 52.0 (45.6-65.9), 55.7 (51.2-65.9), and 53.1 (46.2-63.7) g/L for calves that received colostrum from own dam, different dam, and pooled, respectively. All calves achieved adequate passive immunity. Serum IgG concentrations at $24 \mathrm{~h}$, weaning weights, and proportions of morbidity and mortality were not different among the 3 groups. Our results suggest that on dairy farms where median colostrum IgG concentrations are high and colostrum management is optimal, pooling has a minimal effect on passive immunity and subsequent calf health.

Key words: colostrum, calf, pooling, immunoglobulin

\section{Short Communication}

Colostrum is the first secretion from the mammary gland following parturition and contains IgG, which is essential for providing the neonate with passive immunity (Morrill et al., 2012). Adequate passive transfer (APT) of immunity is achieved when calves are fed a sufficient volume of high-quality colostrum shortly after birth (Lorenz et al., 2011). High-quality colostrum contains >50 g/L IgG (McGuirk and Collins, 2004). Below this IgG threshold, there is a potential risk of failure of passive transfer (FPT), which is associated with increased rates of morbidity and mortality (Todd et al., 2018). Pooling colostrum has associated risks, such as disease transmission and an IgG dilution effect (Williams et al., 2014); however, pooling continues to be practiced on over $40 \%$ of Irish dairy farms (Barry et al., 2019). Despite the associated risk, pooling colostrum can reduce labor requirements associated with feeding newborn calves and has been reported to provide APT of immunity in North American dairy herds (Williams et al., 2014). Furthermore, pooling of colostrum may be 
beneficial, particularly in scenarios where new animals join the herd and might not have been exposed to all diseases prevalent in that herd. Consequently, pooling colostrum allows all calves to ingest colostral immunoglobulins relevant to antigens to which cows were exposed to during the dry period on that farm.

Although studies investigating the effect of pooled colostrum feeding on passive immunity have been conducted in North America (Beam et al., 2009), no such studies have been performed in Ireland, where the calving season is condensed into a 12 -wk period during spring (February-April). The objectives of this study, therefore, were to compare IgG concentrations in colostrum from individual cows and pooled colostrum, as well as serum IgG concentrations, morbidity, and mortality in calves fed their own dam's colostrum, colostrum from a different cow, or pooled colostrum. We hypothesized that pooling bovine colostrum reduces the overall colostrum IgG concentration due to dilution, and consequently, calves fed pooled colostrum achieve lower serum IgG concentrations than calves fed colostrum from individual cows.

A prospective randomized cohort study was conducted at Teagasc, Moorepark Dairy Research Farm (Fermoy, Co. Cork, Ireland). Sixty Holstein Friesian (HF) and $\mathrm{HF} \times$ Jersey cows and 60 calves were enrolled in the study. Calves were stratified based on breed and BW at birth and randomly assigned, within stratum, to their experimental treatment group. The number of calves required per group was calculated by considering multiple factors. Based on a previously reported mean IgG concentration of $112 \mathrm{~g} / \mathrm{L}$ in dairy calves in Ireland (Conneely et al., 2013), a mean difference in IgG concentration of at least $10 \mathrm{~g} / \mathrm{L}$ among the 3 groups, a standard deviation of $10 \mathrm{~g} / \mathrm{L}$, power of $80 \%$, and $\alpha$ of 0.05 , the minimum sample size required per group was 18 calves. To allow for a $10 \%$ dropout rate due to missed samples or incomplete data, 2 calves were added to each group. The final sample size required was 20 calves per group. Commercial software (JMP Pro version 14, SAS Institute Inc., Cary, NC) was used to calculate the sample size. Randomization of calves into each group was achieved by generation of random numbers using Microsoft Excel (Microsoft Corp., Redmond, WA). All calves were enrolled over a period of 6 wk from February to March 2018.

The 3 treatment groups were (1) calves fed unpasteurized colostrum from their own dam ( $\mathbf{O D}, \mathrm{n}=20)$; (2) calves fed unpasteurized colostrum from a different dam (DD, $\mathrm{n}=20$ ); and (3) calves fed unpasteurized pooled colostrum $(\mathbf{P C}, \mathrm{n}=18)$ from a group of cows of variable IgG concentrations. The DD group was included because it represents another colostrum management technique practiced on Irish dairies and is another type of nonpooled colostrum feeding group. In cases where the dam of the calf cannot be milked in time or the dam does not produce colostrum, producers often feed colostrum from a different dam. Effective transfer of maternal leukocytes has been demonstrated in calves fed colostrum from its own dam (Donovan et al., 2007) or from pooled colostrum (Parreño et al., 2004) with no known negative effects of absorption.

All cows were blood sampled before calving, and cows that tested positive for paratuberculosis (Mycobacterium avium ssp. paratuberculosis) or Mycoplasma spp. were not included in the study. Calving was supervised by trained and experienced personnel. Immediately after calving, calves were separated from their dams and $10 \mathrm{~mL}$ of blood (pre-colostral) was collected from the jugular vein into blood tubes without anticoagulant (red top Vacutainer, Becton Dickinson, Franklin Lakes, NJ). Cows were milked with a single portable milking unit (DeLaval Mobile Milking Unit, Carlow, Ireland) within $2 \mathrm{~h}$ of calving. A 250-mL composite sample of colostrum was collected from each cow or pooled colostrum. Calves were fed colostrum at $8.5 \%$ of their birth weight (Conneely et al., 2014), and the required colostral volume was calculated for each individual calf. The required total colostral volume was divided over 2 feedings, one within $2 \mathrm{~h}$ of birth and the other at $12 \mathrm{~h}$ of age. Colostrum was fed by esophageal tubing. Only fresh colostrum was fed, and the source was based on which cows had calved that same day. The pooled colostrum samples comprised samples from 2 to 4 cows, depending on availability. Each calf in the pooled group received their own unique pooled sample. The individual IgG content of each contributor to the pool was not measured.

At $24 \mathrm{~h}$ of age, $10 \mathrm{~mL}$ of blood was collected into tubes without anticoagulant from all calves. Serum was harvested from blood samples after centrifugation at $2,880 \times \mathrm{g}$ for $5 \mathrm{~min}$ at $4^{\circ} \mathrm{C}$. Both colostrum and serum samples were then stored at $-80^{\circ} \mathrm{C}$ until used for IgG determination by single radial immunodiffusion (SRID). Following colostrum feeding, all calves were fed milk replacer thereafter. Calves were initially housed in individual pens for $5 \mathrm{~d}$ and then moved into group pens of 10 to 15 calves. Calves were weaned after reaching a target weight of $95 \mathrm{~kg}$ for $\mathrm{HF}$ calves and 80 $\mathrm{kg}$ for $\mathrm{HF} \times$ Jersey crosses.

Colostrum and serum samples were analyzed for IgG concentrations by collaborators blinded to the group assignments using a commercial SRID kit (Radial Immunodiffusion Test for Quantitation of Bovine IgG in Serum or Plasma, Triple J Farms, Bellingham, WA) according to the manufacturer's recommendations. 
The SRID plates were stored at $4^{\circ} \mathrm{C}$, and contained specific anti-bovine IgG, agarose gel, $0.1 \mathrm{M}$ phosphate buffer ( $\mathrm{pH} 7.0$ ), $0.1 \%$ sodium azide as a bacteriostatic agent, and $1 \mu \mathrm{g} / \mathrm{mL}$ amphotericin $\mathrm{B}$ as an antifungal agent. The IgG concentration determination range of the SRID kit was 0.09 to $1 \mathrm{~g} / \mathrm{L}$ for serum samples collected from calves at $0 \mathrm{~h}$, which allowed detection of IgG; low concentrations of IgG have been reported in serum of calves before colostrum ingestion (Chigerwe et al., 2008). The IgG concentration range of the kit was 1.96 to $28.03 \mathrm{~g} / \mathrm{L}$ for colostrum and serum samples collected at $24 \mathrm{~h}$. Colostrum and serum samples were thawed at room temperature (approximately $20^{\circ} \mathrm{C}$ ) for $24 \mathrm{~h}$. Colostrum samples were diluted at 1:4 or 1:6 and serum samples were diluted 1:2 or 1:4 depending on the IgG concentration; PBS was used as the diluent. Test kits were incubated at room temperature for 30 min before inoculation with $5 \mu \mathrm{L}$ of colostrum or serum per well. Once all samples had been added, plates were incubated at room temperature $\left(20-24^{\circ} \mathrm{C}\right)$ for $24 \mathrm{~h}$. Zones of precipitation in the plate were then measured using a SRID plate reader (Digital RID Plate Reader, The Binding Site, San Diego, CA). The concentration of IgG in the samples was determined by comparing the diameter of the precipitated ring to the standard curve produced by the reference sera provided with the kit. Coefficient of determination $\left(\mathrm{R}^{2}\right)$ values for the standard curves were between 0.96 and 0.99 for the regression equations produced, indicating accurate prediction of the inoculum IgG concentrations. Calves with serum $\operatorname{IgG}$ concentrations $\geq 20 \mathrm{~g} / \mathrm{L}$ at $24 \mathrm{~h}$ were considered to have adequate passive immunity (Chigerwe et al., 2015).

All calves were examined twice daily until weaning by trained personnel blinded to the group assignments. Assessment of morbidity was made based on general demeanor, rectal temperature, presence of diarrhea using fecal consistency scores (McGuirk, 2008), and presence of respiratory disease using respiratory rate and presence of cough, nasal, and ocular discharge (Love et al., 2014). Presence of omphalitis was assessed by digital palpation of the umbilicus, and presence of joint disease was evaluated by digital palpation of joints. The decision to treat sick calves was based on the farm's standard operating procedures. All mortality events and all causes of morbidity were recorded.

Analyses were performed using a commercial software (JMP Pro version 14, SAS Institute Inc.). Normality of the data was determined using the Shapiro-Wilk test. Descriptive statistics were calculated for lactation number, birth weight, colostral IgG and serum IgG concentrations, and weaning weights. Means \pm standard error of mean (SEM) were reported when data were normally distributed, whereas median and $95 \%$ confidence interval (95\% CI) were reported when data were not normally distributed. Differences in distribution of lactation number and colostrum IgG concentrations among colostrum samples from the OD, DD, and PC groups were compared using ANOVA or Kruskal-Wallis test when data were not normally distributed. Differences in birth weights, serum IgG concentrations at 0 and $24 \mathrm{~h}$ in calves fed colostrum from OD, DD, and PC, and weaning weights were compared using ANOVA or Kruskal-Wallis test when data were not normally distributed. Differences in proportions of calves experiencing morbidity and mortality among the 3 groups during the preweaning period were compared using a $\chi^{2}$ test or Fisher's exact test when a cell had $<5$ counts in a $2 \times 2$ frequency table. The results were considered significant when $P<0.05$.

Median (95\% CI) lactation numbers for OD, DD, and PC group cows were $3(1,4), 2(1,3)$, and $1(1,2)$, respectively. Median lactation number was higher $(P$ $=0.01)$ in the $\mathrm{OD}$ than in the $\mathrm{PC}$ group. Lactation numbers were not different between OD and DD $(P=$ $0.99)$ or $\mathrm{DD}$ and $\mathrm{PC}(P=0.18)$ group cows. Median (95\% CI) colostrum IgG concentrations were 99.4 (81.8, 111.5), 95.2 (84.1, 107.2), and $100.7(90.5,104.4) \mathrm{g} / \mathrm{L}$ for $\mathrm{OD}, \mathrm{DD}$, and $\mathrm{PC}$ group cows, respectively. Colostrum IgG concentrations, summarized in Table 1, were not different $(P=0.93)$ among the OD, DD, and PC group cows.

Table 1. Summary of median (95\% CI) colostral IgG concentrations $(\mathrm{g} / \mathrm{L})$, serum IgG concentrations $(\mathrm{g} / \mathrm{L})$, and birth and weaning weights of calves fed colostrum from different sources

\begin{tabular}{lccr}
\hline & \multicolumn{3}{c}{ Colostrum source } \\
\cline { 2 - 4 } Variable & Different dam & Own dam & Pooled colostrum \\
\hline 0-h serum IgG $(\mathrm{g} / \mathrm{L})$ & $0.09(0.09,0.4)^{\mathrm{a}}$ & $0.09(0.09,0.09)^{\mathrm{a}}$ & $0.09(0.09,0.09)^{\mathrm{a}}$ \\
Colostral IgG $\mathrm{g} / \mathrm{L})$ & $95.2(84.1,107.2)^{\mathrm{a}}$ & $99.4(81.8,111.5)^{\mathrm{a}}$ & $100.7(90.5,104.4)^{\mathrm{a}}$ \\
24-h serum IgG $(\mathrm{g} / \mathrm{L})$ & $55.7(51.2,65.9)^{\mathrm{a}}$ & $52.0(45.6,65.9)^{\mathrm{a}}$ & $53.1(46.2,63.7)^{\mathrm{a}}$ \\
Birth weight $(\mathrm{kg})$ & $34.3(30.6,35.0)^{\mathrm{a}}$ & $33.3(28.0,36.5)^{\mathrm{a}}$ & $34.0(31.0,36.0)^{\mathrm{a}}$ \\
Weaning weight $(\mathrm{kg})$ & $91.7(88.5,94.5)^{\mathrm{a}}$ & $93.7(90.8,95.5)^{\mathrm{a}}$ & $94.0(86.0,95.5)^{\mathrm{a}}$ \\
\hline
\end{tabular}

${ }^{a}$ Values within a row with the same superscript did not differ $(P<0.05)$. 
Median (95\% CI) birth weights, weaning weights, and serum IgG concentrations at 0 and $24 \mathrm{~h}$ from calves fed colostrum from OD, DD, and PC cows are summarized in Table 1. Serum IgG levels at $0 \mathrm{~h}$, before colostrum ingestion, was $0.09 \mathrm{~g} / \mathrm{L}$ across all calf groups, indicating that the calves had not nursed before IgG levels were measured. We found no differences in median birth weights $(P=0.97)$, serum IgG concentrations at $0 \mathrm{~h}$ $(P=0.19)$ or $24 \mathrm{~h}(P=0.62)$, or weaning weights $(P$ $=0.59)$ among the calves. All calves achieved adequate transfer of immunity.

Twenty-five morbidity events were recorded: 8,10 , and 7 across the OD, DD, and PC treatment groups, respectively. The proportion of calves experiencing morbidity did not differ $(P=0.60)$ among the groups, with diagnosed events consisting of diarrhea or respiratory disease. Twelve of the morbidity events required medical treatment with antimicrobials or oral electrolytes, and a combination of both in some cases; 2, 7, and 3 calves from the OD, DD, and PC groups were treated, respectively. The proportion of calves that experienced morbidity and were treated did not differ $(P=0.13)$ among the groups. All calves survived to weaning.

Our study results indicated no differences in colostral IgG concentrations from individual cows compared with that of pooled high-quality colostrum. We also did not find differences in serum IgG concentrations at 24 $\mathrm{h}$ or in morbidity or mortality among calves fed colostrum from their own dam, a different dam, or pooled colostrum. In contrast to our hypothesis, pooling bovine colostrum did not affect colostral IgG concentration compared with feeding colostrum from individual cows, and calves fed pooled colostrum achieved similar serum IgG concentrations to calves fed colostrum from individual cows. Our results differ from previous reviews (Weaver et al., 2000) and observational studies in North American dairies (Beam et al., 2009), which reported increased odds of FPT of immunity among calves fed pooled colostrum. However, a recent study (Williams et al., 2014) reported APT of immunity in calves fed pooled colostrum on a Californian dairy farm. A possible reason for these different results may be the high median colostral IgG in both our study and that of Williams et al. (2014). Thus, when the colostral IgG concentration is higher, pooling of colostrum has an insignificant effect on the quantity of IgG delivered to the calf. Many studies assessing colostrum and FPT also investigated other variables affecting transfer of colostral immunity, such as timing of colostrum ingestion, method of ingestion, colostrum pasteurization, and the presence or absence of dystocia. In contrast, our study focused on the effect of pooling colostrum alone with other variables similar among calves. A previous study by Kehoe et al. (2011) reported that IgG in colostrum increased with parity, with cows in first, second, third, and fourth or greater lactations producing colostrum with IgG concentrations of 83.5, 92.9, 107.4, and 113.3 $\mathrm{g} / \mathrm{L}$, respectively. In our study, median lactation number was higher in OD than in PC group cows. Despite this difference in lactation stage, all calves fed pooled colostrum achieved APT of immunity.

Pooling colostrum is a common practice on Irish dairy farms. Kennedy et al. (2014) reported that $73.5 \%$ of 312 randomly selected Irish dairy herds pooled colostrum. The mean (and $95 \%$ prediction interval) total costs per calf with FPT were estimated to be $€ 60$ (€10-€109) and $€ 80(€ 20-€ 139)$ for dairy and beef, respectively (Raboisson et al., 2016). Thus, economic losses due to FPT are significant to Irish farmers, and achieving APT in calves is an area of colostral management that requires improvement. The national prevalence of FPT in dairy herds in the United States is reported to be $19.2 \%$ (Beam et al., 2009). Irish surveillance data reported FPT prevalences of 50, 46, 38, and $38 \%$ in 2013, 2014, 2015, and 2016, respectively, based on the zinc sulfate turbidity test on samples submitted voluntarily by veterinary practitioners (AFBI/DAFM, 2016). Although the zinc sulfate turbidity test is not considered the reference for assessing FPT in calves, and submissions were likely biased samples submitted by veterinarians due to suspicion of FPT, the data (AFBI/DAFM, 2016) reflect potential deficiencies in colostrum management practices on Irish dairy farms. Recent studies indicated that $49 \%$ of Irish calves were classified as having FPT when optimum globulin cutoff points of 29 to $34 \mathrm{~g} / \mathrm{L}$ were used (Todd et al., 2018). Based on the high prevalence of pooling colostrum and FPT on Irish dairy farms, as well as the financial consequences of FPT, it is of practical interest to farmers to ensure that pooling colostrum does not contribute to FPT.

Although results from the present study indicated that pooling colostrum did not affect achievement of APT, these results should be interpreted with caution because the herd used in this study had relatively high median colostrum IgG concentrations, and all calves were fed colostrum within $2 \mathrm{~h}$ after birth. Consequently, pooling colostrum might be undesirable in herds with relatively lower colostrum IgG concentrations or when other factors that maximize acquisition of APT of immunity (such as time of feeding colostrum and volume fed) are not optimized. Less optimal feeding scenarios that affect effectiveness of pooling colostrum include feeding colostrum later in the 24-h optimal window of absorption (Mech et al., 2011), feeding colostrum contaminated with bacteria (Short et al., 2016), and 
pooling colostrum with a very high IgG concentration with colostrum with a very low $\operatorname{IgG}(<25 \mathrm{~g} / \mathrm{L})$ concentration (Weaver et al., 2000). Pooling colostrum is not without risk because it has been demonstrated that pathogens such as Mycobacterium avium ssp. paratuberculosis (Stabel et al., 2014) and Mycoplasma (Sasaoka et al., 2015) can be transmitted in colostrum. Pasteurization of the colostrum was not performed in this study because it is not routine practice on Irish dairy farms. However, the cows were screened for Mycobacterium avium ssp. paratuberculosis and Mycoplasma before their colostrum was included in the study.

The main limitation of our study is that a single farm with high colostrum IgG concentrations and optimum colostrum feeding management was enrolled, whereas other factors that affect passive immunity of colostrum were similar among calves. Thus, the external validity of our results might be limited. Replicating the study across multiple, nonresearch commercial dairies to ensure applicability to the typical Irish dairy farm is recommended. However, it should be noted that to examine the influence of pooling alone on the achievement of APT, other variables that effect achievement of APT were controlled. A study to determine the national prevalence of FPT in Irish dairy herds is warranted. We also recommend determination of colostral IgG concentration cut-off points for when to pool and not to pool colostrum.

In conclusion, pooling had no effect on colostrum IgG concentration or serum IgG concentration of calves, likely because of the high median colostrum IgG concentration. In herds where colostrum IgG concentrations are high, the influence of a dilution effect lowering IgG concentration when pooled is minimized. On dairies with an overall high median colostral IgG and optimum colostral management practices, pooling of colostrum is a feasible strategy to reduce the labor associated with calf rearing on farms.

\section{ACKNOWLEDGMENTS}

University of California Davis Global Affairs Seed Grants funded this research and did not have input into the design, collection, analysis, or interpretation of the data, drafting of the manuscript, or decisions to submit the manuscript for publication. The authors thank Lisa Gamsjaeger (University of Calgary, Faculty of Veterinary Medicine, Alberta, Canada) and Devra Kennedy, Paige Gillooley, and Sarah Blasczynski, livestock medicine and surgery technicians at the William Pritchard Veterinary Medicine Teaching Hospital (Davis, CA) for their technical assistance.

\section{REFERENCES}

AFBI/DAFM. 2016. All-Island Animal Disease Surveillance Report 2016. A Joint AFBI/DAFM Veterinary Laboratories Publication. Department of Agriculture, Food and the Marine/Agriculture Food and Biosciences Institute. Accessed Feb. 4, 2019. https: //www.agriculture.gov.ie/media/migration/animalhealthwelfare/ labservice/rvlreports/AIDSRReport016230118.pdf.

Barry, J., E. A. M. Bokkers, D. P. Berry, I. J. M. de Boer, J. McClure, and E. Kennedy. 2019. Associations between colostrum management, calf related hygiene practices and passive immunity and mortality among pre-weaned Irish dairy calves. J. Dairy Sci. 102:10266-10276. https://doi.org/10.3168/jds.2019-16815.

Beam, A. L., J. E. Lombard, C. A. Kopral, L. P. Garber, A. L. Winter, J. A. Hicks, and J. L. Schlater. 2009. Prevalence of failure of passive transfer of immunity in newborn heifer calves and associated management practices on US dairy operations. J. Dairy Sci. 92:3973-3980. https://doi.org/10.3168/jds.2009-2225.

Chigerwe, M., J. V. Hagey, and S. S. Aly. 2015. Determination of neonatal serum immunoglobulin $G$ concentrations associated with mortality during the first 4 months of life in dairy heifer calves. J. Dairy Res. 82:400-406. https://doi.org/10.1017/ S0022029915000503.

Chigerwe, M., J. W. Tyler, D. W. Nagy, and J. R. Middleton. 2008. Frequency of detectable serum IgG concentrations in precolostral calves. Am. J. Vet. Res. 69:791-795. https://doi.org/10.2460/ajvr 69.6.791.

Conneely, M., D. P. Berry, J. P. Murphy, I. Lorenz, M. L. Doherty, and E. Kennedy. 2014. Effect of feeding colostrum at different volumes and subsequent number of transition milk feeds on the serum immunoglobulin $\mathrm{G}$ concentration and health status of dairy calves. J Dairy Sci. 97:6991-7000. https://doi.org/10.3168/jds.2013-7494.

Conneely, M., D. P. Berry, R. Sayers, J. P. Murphy, I. Lorenz, M. L. Doherty, and E. Kennedy. 2013. Factors associated with the concentration of immunoglobulin $\mathrm{G}$ in the colostrum of dairy cows. Animal 7:1824-1832. https://doi.org/10.1017/S1751731113001444.

Donovan, D. C., A. J. Reber, J. D. Gabbard, M. Aceves-Avila, K. L. Galland, K. A. Holbert, L. O. Ely, and D. J. Hurley. 2007. Effect of maternal cells transferred with colostrum on cellular responses to pathogen antigens in neonatal calves. Am. J. Vet. Res. 68:778782. https://doi.org/10.2460/ajvr.68.7.778.

Kehoe, S. I., A. J. Heinrichs, M. L. Moody, C. M. Jones, and M. R. Long. 2011. Comparison of immunoglobulin G concentrations in primiparous and multiparous bovine colostrum. Prof. Anim. Sci. 27:176-180. https://doi.org/10.15232/S1080-7446(15)30471-X.

Kennedy, A. E., E. F. O'Doherty, N. Byrne, J. O'Mahony, E. M. Kennedy, and R. G. Sayers. 2014. A survey of management practices on Irish dairy farms with emphasis on risk factors for Johne's disease transmission. Ir. Vet. J. 67:27. https://doi.org/10.1186/ s13620-014-0027-9.

Lorenz, I., J. F. Mee, B. Earley, and S. J. More. 2011. Calf health from birth to weaning. I. General aspects of disease prevention. Ir. Vet. J. 64:10. https://doi.org/10.1186/2046-0481-64-10.

Love, W. J., T. W. Lehenbauer, P. H. Kass, A. L. Van Eenennaam, and S. S. Aly. 2014. Development of a novel clinical scoring system for on-farm diagnosis of bovine respiratory disease in preweaned dairy calves. PeerJ 2:e238. https://doi.org/10.7717/peerj.238.

McGuirk, S. M. 2008. Disease management of dairy calves and heifers. Vet. Clin. North Am. Food Anim. Pract. 24:139-153. https://doi .org/10.1016/j.cvfa.2007.10.003.

McGuirk, S. M., and M. Collins. 2004. Managing the production, storage, and delivery of colostrum. Vet. Clin. North Am. Food Anim. Pract. 20:593-603. https://doi.org/10.1016/j.cvfa.2004.06.005.

Mech, A., A. Dhali, K. K. Baruah, R. K. Singh, S. K. Mondal, and C. Rajkhowa. 2011. Effect of method and time of first colostrum feeding on serum immunoglobulin concentration, health status and body weight gain in mithun (Bos frontalis) calves. J. Anim. Physiol. Anim. Nutr. (Berl.) 95:756-761. https://doi.org/10.1111/ j.1439-0396.2010.01105.x. 
Morrill, K. M., E. Conrad, A. Lago, J. Campbell, J. Quigley, and H. Tyler. 2012. Nationwide evaluation of quality and composition of colostrum on dairy farms in the United States. J. Dairy Sci. 95:3997-4005. https://doi.org/10.3168/jds.2011-5174.

Parreño, V., C. Béjar, A. Vagnozzi, M. Barrandeguy, V. Costantini, M. I. Craig, L. Yuan, D. Hodgins, L. Saif, and F. Fernández. 2004. Modulation by colostrum-acquired maternal antibodies of systemic and mucosal antibody responses to rotavirus in calves experimentally challenged with bovine rotavirus. Vet. Immunol. Immunopathol. 100:7-24. https://doi.org/10.1016/j.vetimm.2004 .02 .007 .

Raboisson, D., P. Trillat, and C. Cahuzac. 2016. Failure of passive immune transfer in calves: A meta-analysis on the consequences and assessment of the economic impact. PLoS One 11:e0150452. https: //doi.org/10.1371/journal.pone.0150452.

Sasaoka, F., J. Suzuki, T. Hirata, T. Ichijo, K. Furuhama, R. Harasawa, and H. Satoh. 2015. Vertical transmission of Mycoplasma wenyonii in cattle, supported by analysis of the ribonuclease P RNA gene. Acta Vet. Hung. 63:271-274. https://doi.org/10.1556/004 .2015.025.

Short, D. M., D. A. Moore, and W. M. Sischo. 2016. A randomized clinical trial evaluating the effects of oligosaccharides on transfer of passive immunity in neonatal dairy calves. J. Vet. Intern. Med. 30:1381-1389. https://doi.org/10.1111/jvim.13949.

Stabel, J. R., L. Bradner, S. Robbe-Austerman, and D. C. Beitz. 2014. Clinical disease and stage of lactation influence shedding of Mycobacterium avium subspecies paratuberculosis into milk and colos- trum of naturally infected dairy cows. J. Dairy Sci. 97:6296-6304. https://doi.org/10.3168/jds.2014-8204.

Todd, C. G., M. McGee, K. Tiernan, P. Crosson, E. O'Riordan, J. McClure, I. Lorenz, and B. Earley. 2018. An observational study on passive immunity in Irish suckler beef and dairy calves: Tests for failure of passive transfer of immunity and associations with health and performance. Prev. Vet. Med. 159:182-195. https://doi.org/10 .1016/j.prevetmed.2018.07.014.

Weaver, D. M., J. W. Tyler, D. C. VanMetre, D. E. Hostetler, and G. M. Barrington. 2000. Passive transfer of colostral immunoglobulins in calves. J. Vet. Intern. Med. 14:569-577. https://doi.org/10 .1111/j.1939-1676.2000.tb02278.x.

Williams, D. R., P. Pithua, A. Garcia, J. Champagne, D. M. Haines, and S. S. Aly. 2014. Effect of three colostrum diets on passive transfer of immunity and preweaning health in calves on a California dairy following colostrum management training. Vet. Med. Int. 2014:1-9. https://doi.org/10.1155/2014/698741.

\section{ORCIDS}

Ailbhe King (으 https://orcid.org/0000-0001-6002-0351

Munashe Chigerwe ๑ https://orcid.org/0000-0001-6841-2448

John Barry (i) https://orcid.org/0000-0001-9792-7264

Maire C. Rayburn (1) https://orcid.org/0000-0002-1220-4639

Emer Kennedy @ https://orcid.org/0000-0002-9284-5304 